REVISTA CIENCIAS BIOMÉDICAS

RESEÑA BIBLIOGRÁFICA

\title{
GUÍA SEMIOLÓGICA GO
}

\author{
BORRE-ARRIETA ORLANDO \\ RODRÍGUEZ-YANCES BENJAMÍN \\ SALCEDO-RAMOS FRANCISCO
}

Desde los inicios del Departamento de Ginecología y Obstetricia de la Universidad de Cartagena-Colombia, hace más de medio siglo, se ha venido enseñando la Cátedra de Semiología, la cual ha sido desarrollada sin uniformidad en la comunicación de algunos conceptos, lo cual puede generar confusión. Muchas de esas conceptualizaciones han sido entregadas de generación en generación, sin una fundamentación bibliográfica suficiente que homogenice la transmisión del conocimiento y la adecuada apropiación por parte de los estudiantes de pregrado.

Desde la llegada al DepartaGUIA SEMIOLÓGICA GO mento de Ginecología y Obstétrica de la Universidad de Cartagena, de especialistas formados por el Centro Latinoamericano de Perinatología (CLAP), por escuelas Españolas, por instituciones de los Estados Unidos e incluso de otras universidades colombianas, se ha incrementado la diversidad de algunos criterios semiológicos por la carencia de convocatoria a establecer consensos.

Es por ello que se ha adelantado investigación bibliográfica que sirva de base para el momento de adelantar la instrucción semiológica en Ginecología y Obstetricia.

En Colombia fue publicado en el año 2009 un trabajo extenso y meritorio del Departamento de Ginecología y Obstetricia de la Universidad Industrial de Santander - Bucaramanga, elaborado por la doctora Carolina Parra Meza y dirigido por el doctor Miguel Ángel Alarcón Nivia, profesor titular de dicha universidad, con el título "La semiología clínica en ginecología y obstetricia".

Hoy en día, los factores legales, los locativos para la práctica, el escaso tiempo dedicado al desarrollo de la asignatura, el aumento de la población estudiantil, los derechos humanos del paciente, la oposi- 
ción parcial de las empresas prestadoras de salud para que la instrucción se desarrolle en forma satisfactoria y directa sobre el paciente, hacen que las universidades utilicen otros métodos para la enseñanza de la propedéutica como la simulación, la cual debe entenderse como la etapa introductora para el estudiante antes de enfrentar al paciente. Importante aporte de sus autores, libro que está llamado a ser pronto, documento básico para el estudiante de pregrado.

\section{HISTORIA DE LA MEDICINA EN CARTAGENA DE INDIAS}

\section{GHISAYS-GANEM MIGUEL ÁNGEL}

El autor en las frases que prologan el libro dice: "De mis lejanos años de estudiante de medicina de la Universidad de Cartagena, recuerdo con alegría las lecciones de historia de la medicina que nos dictaba con lujo de competencia el profesor Mario Fernández Mendoza, lecciones que finalizaban con un nutrido aplauso de los estudiantes. Las enjundiosas conferencias dictadas con gran calor por el profesor Fernández, despertaron en mí un gran interés por el estudio de la historia de la medicina, desde entonces, aprovechaba todas las oportunidades de conversar sobre el tema; no solo con el profesor Fernández, sino también con el profesor Moisés Pianeta Muños, gran conocedor de la historia de la medicina en Cartagena".

El profesor Miguel Ángel Ghisays-Ganem, profesor de la Facultad de Medicina de la Universidad de Cartagena en uso de retiro, además señaló: "por esas calendas existían pocas oportunidades de adquirir libros sobre temas especializados. Las librerías en Cartagena eran muy pocas y se podían contar con los dedos de una mano. En una de mis frecuentes visitas a una de ellas, tuve la oportunidad de adquirir un maravilloso tratado llamado "La historia de la medicina" del profesor Douglas Guthrie, texto que se convirtió en mi libro de cabecera, no solo amplió mis conocimientos sino me sensibilizó sobre el valor inmenso que tiene la historia en el devenir de los pueblos".
El libro presenta la historia de una facultad centenaria apoyándose en documentos primarios y en otras fuentes que han develado los aconteceres de la escuela médica de la Universidad de Cartagena. Enhorabuena, puesto que existe la apremiante necesidad de abordar y profundizar en espacios, hechos y personalidades, que fraguaron la realidad actual de la Facultad de Medicina de la Universidad de Cartagena, oportunidad para comprender las problemáticas del presente a partir de las vivencias y las decisiones del ayer.

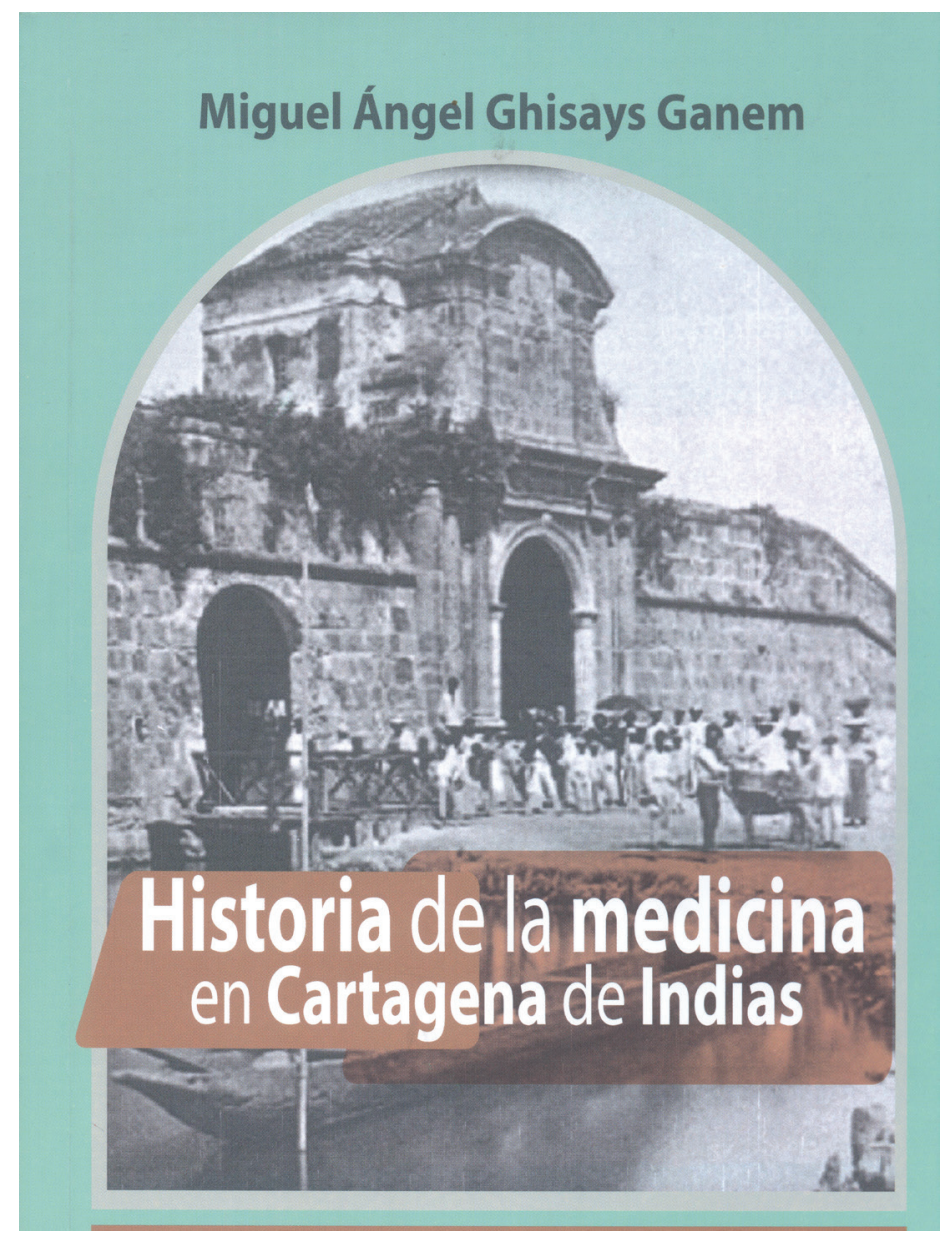

